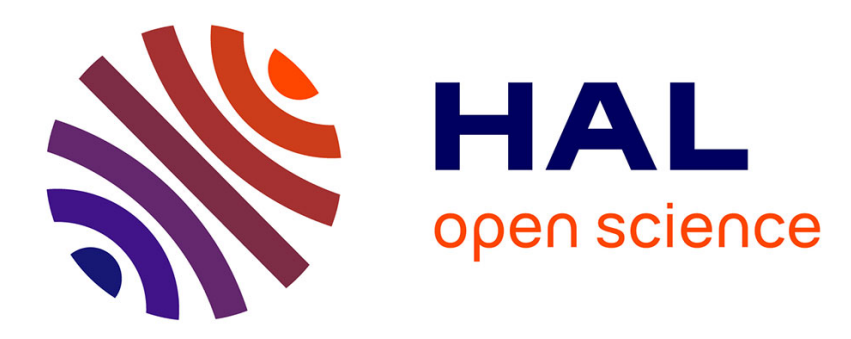

\title{
Selecting the components of composites
}

\author{
M. Ashby
}

\section{To cite this version:}

M. Ashby. Selecting the components of composites. Journal de Physique IV Proceedings, 1993, 03

(C7), pp.C7-1595-C7-1600. 10.1051/jp4:19937250 . jpa-00251889

\section{HAL Id: jpa-00251889 https://hal.science/jpa-00251889}

Submitted on 1 Jan 1993

HAL is a multi-disciplinary open access archive for the deposit and dissemination of scientific research documents, whether they are published or not. The documents may come from teaching and research institutions in France or abroad, or from public or private research centers.
L'archive ouverte pluridisciplinaire HAL, est destinée au dépôt et à la diffusion de documents scientifiques de niveau recherche, publiés ou non, émanant des établissements d'enseignement et de recherche français ou étrangers, des laboratoires publics ou privés. 


\section{Selecting the components of composites}

\section{M.F. ASHBY}

Engineering Design Centre, Engineering Department, Trumpington Street, Cambridge CB2 1PZ, England

\section{ABSTRACT}

Composites combine the properties of two or more components. Conceptual tools are developed which guide the selection of components for making composites which maximise one or more aspect of thermo-mechanical performance.

\section{INTRODUCTION}

Any two materials could, in principle, be combined to make a composite (Fig. 1), and they might be mixed in many geometries (Fig. 2). This paper outlines a scheme for identifying the component materials which could be used to make composites with potentially attractive properties. Three concepts are used. The first is that of performance indices which isolate the combination of material properties that maximise performance; the second is that of materials-selection charts onto which both material properties and performance indices can be plotted; and the third is the use of bounds to define the envelope of properties accessible to a given composite systems [1].

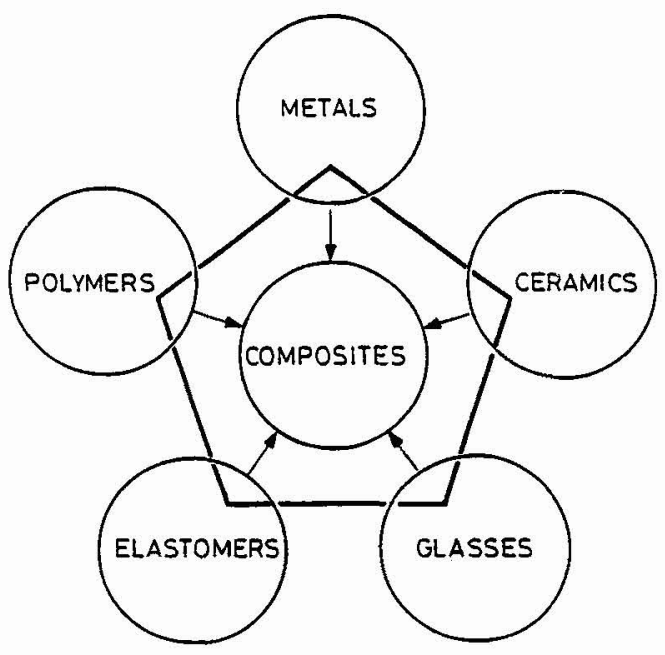

Fig. 1. The material classes from which composites are made.

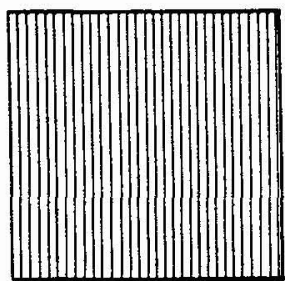

UNIDIRECTIONAL

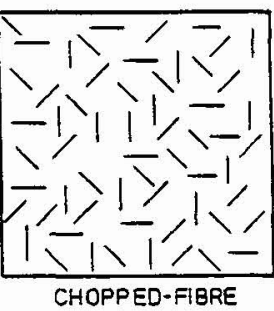

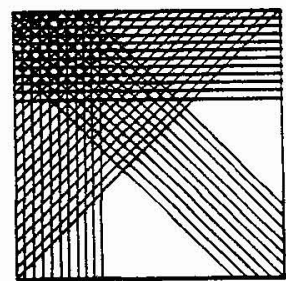

LAMINATES

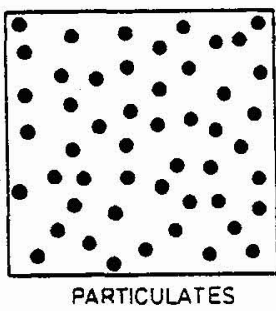

Fig. 2. Uni-directional fibrous composite, laminated composite, chopped-fibre and particulate composite. 


\section{PERFORMANCE INDICES, SELECTION CHARTS AND PROPERTY BOUNDS}

A performance index is a property or group of properties which measures the effectiveness of a material in performing a given function [2]. The best material for a light, stiff tie (a tensile member) is that with the greatest value of the specific stiffness, $E / p$. But it is not always so straightforward. The lightest beam (a member loaded in bending) with a prescribed stiffness is that made of the material with the greatest value of $E^{1 / 2} / \rho$; the best springs are those made of materials with the highest values of $\sigma_{\mathrm{f}}^{2} / \mathrm{E}$, where $\sigma_{\mathrm{f}}$ is the yield or fracture stress; the precision device which is least distorted by heat is that made of the material with the highest value of $\lambda \alpha$, where $\lambda$ is the thermal conductivity and $\alpha$ is the expansion coefficient. The performance indices are $E^{1 / 2} / \rho, \sigma_{f}^{2} / E$ and $\lambda / \alpha$. The best choice of material is that with the largest value of the appropriate index. The indices provide a set of pointers; they direct the composite-developer towards material combinations which, potentially, offer something new.

The indices, frequently, combine two or more properties. This suggests the notion of constructing charts on which one property is plotted against another in such a way that both the properties and their combinations can be examined. Figure 3 illustrates the idea. The axes are Young's modulus $E / \rho$ and density $\rho$. The scales are logarithmic, and span a range so wide that almost all engineering materials are included. The index $E / \rho$ appears on these axes as a family of parallel lines of slope 1 ; the index $E^{1 / 2} / \rho$ appears as a family of slope 2 . Other charts give optimal selection via other indices. Charts and method are fully described in ref [2] and in the paper by Ashby and Cebon in these Proceedings.

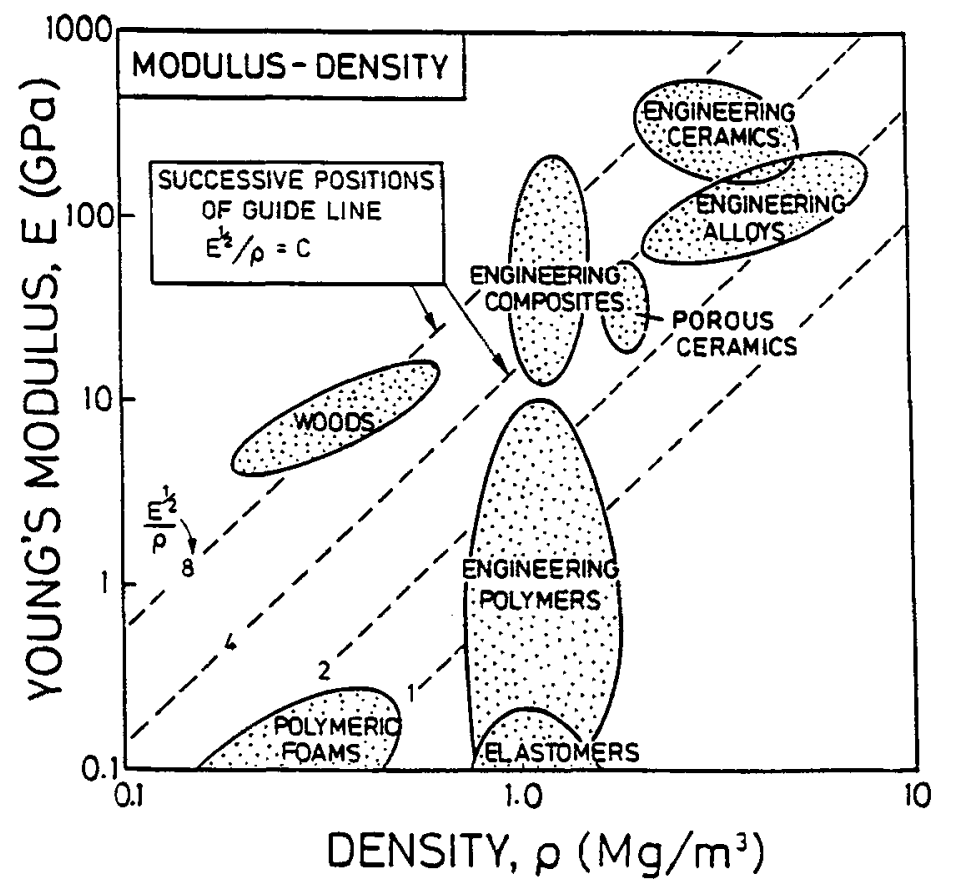

Fig. 3. A schematic Selection Chart, in which modulus $E$ is plotted against density $\rho$. 
On a macroscopic scale a composite behaves like a homogeneous solid with its own set of thermo-mechanical properties. Calculating these precisely is difficult. It is much easier to bracket them by bounds or limits: upper and lower values between which the properties lie. For most properties, this can be done accurately enough to identify interesting possibilities.

Seven mechanical and thermal properties are of direct interest in assessing the potential of a new composite: density, modulus, strength, toughness, thermal conductivity, expansion coefficient and heat capacity (Table 1); others, like fracture toughness and thermal diffusivity, are calculated from them. In this section we assemble bounds or limits for material properties. The term "bound" will be used to describe a rigorous boundary, one which the value of the property cannot - subject to certain assumptions - exceed or fall below. But it is not always possible to derive bounds; then the best than can be done is to derive "limits" outside which it is unlikely that the value of the property will lie. In what follows, density and specific heat are calculated exactly; moduli, thermal expansion and thermal conductivity and diffusivity are bracketed by bounds; but strength and toughness can only be enclosed by limits. As far as possible, all are based on micromechanical modelling; their origins are detailed in ref [1]. The important point is that the bounds or limits bracket the properties of all arrangements of matrix and reinforcement shown in Fig. 2; by using them we escape from the need to model individual geometries.

Density. When a volume fraction $f$ of a reinforcement $r$ (density $\rho_{r}$ ) is mixed with a volume fraction $(1-f)$ of a matrix $m$ (density $\rho_{m}$ ) to form a composite with no residual porosity or voidspace, the composite density is given exactly by a rule of mixtures (an arithmetic mean, weighted by volume fraction)

$$
\rho_{\mathrm{r}}=\mathrm{f} \rho_{\mathrm{r}}+(1-\mathrm{f}) \rho_{\mathrm{m}}
$$

Modulus. The modulus of a composite is bracketed by the well-known Voigt and Reuss bounds:

$$
\begin{aligned}
& E_{r}=f E_{r}+(1-f) E_{m} \\
& E_{x}=\frac{E_{m} E_{r}}{f E_{m}+(1+f) E_{x}}
\end{aligned}
$$

Here $E_{r}$ is the Young's modulus of the reinforcement and $E_{m}$ that of the matrix.

Strength. The upper bound is, as with modulus, a rule of mixtures

$$
\left(\sigma_{\mathrm{f}}\right)_{\mathrm{u}}=\mathrm{f}\left(\sigma_{\mathrm{f}}\right)_{\mathrm{s}}+(1-\mathrm{f})\left(\sigma_{\mathrm{f}}\right)_{\mathrm{m}}
$$

where $\left(\sigma_{\mathrm{f}}\right)_{\mathrm{m}}$ is the strength of the matrix and $\left(\sigma_{\mathrm{f}}\right)_{\mathrm{r}}$ is that of the reinforcement. A lower limit is the yield strength of the matrix enhanced slightly by the plastic constraint imposed by the reinforcement $[14,15]$

$$
\left(\sigma_{\mathrm{f}}\right)_{1}=\left(\sigma_{\mathrm{f}}\right)_{\mathrm{m}} 1+\frac{1}{16}\left(\frac{\mathrm{f}^{1 / 2}}{1-\mathrm{f}^{1 / 2}}\right)
$$

The bounds are wide, but they still allow important conclusions to be reached.

Specific Heat. The specific heats of solids at constant pressure, $\mathrm{C}_{\mathrm{p}}$, are almost the same as those at constant volume, $\mathrm{C}_{\mathrm{v}}$. If they were identical, the heat capacity per unit volume of a composite would, like the density, be given exactly by a rule-of-mixtures

$$
\rho C_{p}=f \rho_{r}\left(C_{p}\right)_{r}+(1-f) \rho_{m}\left(C_{p}\right)_{m}
$$

where $\left(C_{p}\right)_{r}$ is the specific heat of the reinforcement and $\left(C_{p}\right)_{m}$ is that of the matrix. 
Thermal Expansion Coefficient. We use the approximate lower bounds of Levin

and the upper bound of Schapery

$$
\alpha_{L}=\frac{E_{x} \alpha f+E_{m} \alpha_{m}(1-f)}{E_{r} f+E_{m}(1-f)}
$$

$$
\sigma_{\mathrm{u}}=\mathrm{f} \alpha_{\mathrm{r}}\left(1+v_{\mathrm{r}}\right)+(1-\mathrm{f}) \alpha_{\mathrm{m}}\left(1+v_{\mathrm{m}}\right)-\alpha_{\mathrm{L}}\left[\mathrm{f} v_{\mathrm{r}}+(1-\mathrm{f}) \mathrm{v}_{\mathrm{m}}\right]
$$

where $\alpha_{\mathrm{r}}$ and $\alpha_{\mathrm{m}}$ are the two expansion coefficients and $v_{\mathrm{r}}$ and $v_{\mathrm{m}}$ the Poisson's ratios.

Thermal Conductivity. A composite containing parallel continuous fibres has a conductivity, parallel to the fibres, given by a rule-of mixtures

$$
\lambda_{\mathrm{u}}=\mathrm{f} \lambda_{\mathrm{s}}+(1-\mathrm{f}) \lambda_{\mathrm{m}}
$$

This is an upper bound: in any other direction the conductivity is lower. The transverse conductivity of parallel-fibre composite (again assuming good bonding and thermal contact) lies near the lower bound first derived by Maxwell

$$
\lambda_{L}=\left(\frac{\lambda_{r}+2 \lambda_{m}-2 f\left(\lambda_{m}-\lambda_{r}\right)}{\lambda_{r}+2 \lambda_{m}+f\left(\lambda_{m}-\lambda_{r}\right)}\right)
$$

Particulate composites, too, have a conductivity near this bound. Details are given in [1], in which bounds and limits for thermal diffusivity, toughness and fracture toughness are also described.

\section{APPLICATIONS: ESTIMATING THE POTENTIAL OF COMPOSITE SYSTEMS}

Now comes the last step: that of combining the indices, the charts and the bounds to design composites for specific applications. Two examples are developed, but it will be clear that the method is a general one, and can be extended further [1].

\section{Composite Design for Stiffness at Minimum Weight}

Consider, first, design of a composite for a light, stiff, beam of fixed section-shape, to be loaded in bending. The efficiency is measured by the index $M=E^{1 / 2} / \rho$. Imagine, as an example, that the beam is at present made of an aluminium alloy and that the alloy could be stiffened by incorporating particles or fibres of beryllium $(\mathrm{Be})$ or of alumina $\left(\mathrm{Al}_{2} \mathrm{O}_{3}\right)$ in it. Both are much stiffer than aluminium.

Figure 4 is a small part of the E- $\rho$ chart introduced in the last section. Three groups of materials are shown: aluminium and its alloys; beryllium; and a range of aluminas. Composites made by mixing them have densities given exactly by equation (3), and moduli which are bracketed by the bounds of equations (4) and (5). Both of these moduli depend on volume fraction of reinforcement, and through this, on density. Upper and lower bounds for the modulus-density relationship can thus be plotted onto the E- $\rho$ chart using volume fraction $f$ as a parameter, as shown in Fig. 4. Any composite made by combining aluminium with beryllium will have a modulus which lies somewhere in the Al-Be envelope; any made of aluminium and alumina will have a modulus contained in the envelope for $\mathrm{Al}-\mathrm{Al}_{2} \mathrm{O}_{3}$. Fibrous reinforcement gives a longitudinal modulus (that parallel to the fibres) near the upper bound; particulate reinforcement or transversely loaded fibres give moduli near the lower one. 
Superimposed on Fig. 4 is a grid showing the performance indices $M$ - the quantity we wish to maximise. The bound-envelope for $\mathrm{Al}-\mathrm{Be}$ composites extends almost normal to the grid, while that for $\mathrm{Al}-\mathrm{Al}_{2} \mathrm{O}_{3}$ is, initially, parallel to the $\mathrm{M}$ grid: $30 \%$ of particulate $\mathrm{Al}_{2} \mathrm{O}_{3}$ gives almost no gain in $\mathrm{M}$. The underlying reason is clear: both $\mathrm{Be}$ and $\mathrm{Al}_{2} \mathrm{O}_{3}$ increases the modulus, but only $\mathrm{Be}$ decreases the density; both indices are more sensitive to density than to modulus.

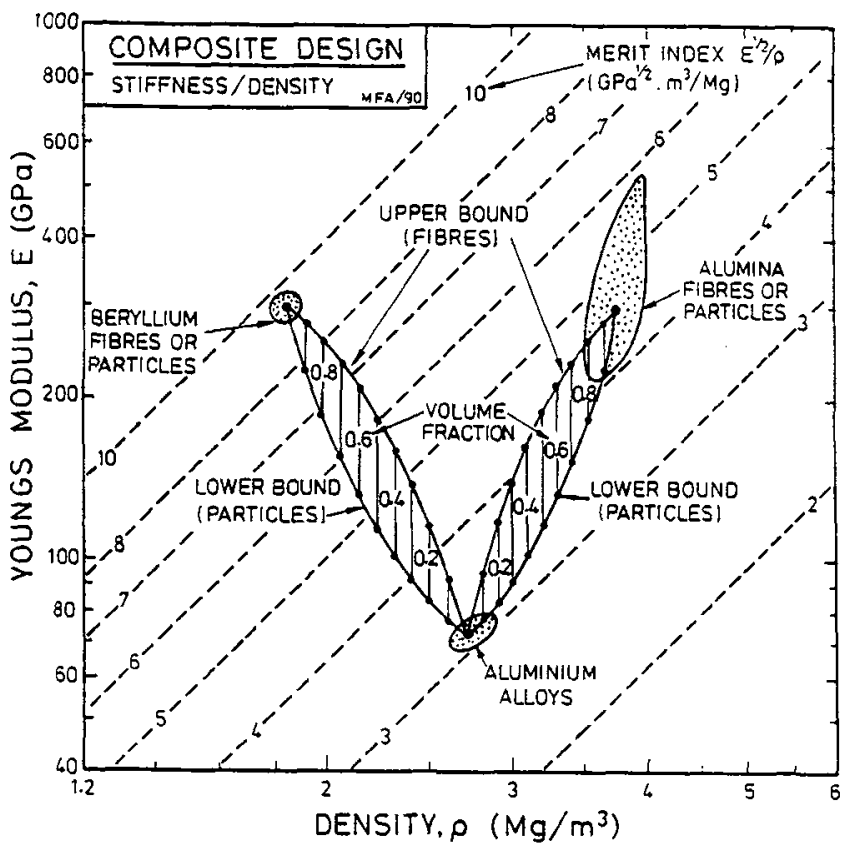

Fig. 4 A part of modulus-density space, showing aluminium alloys, beryllium and alumina. The moduli of $\mathrm{Al}-\mathrm{Be}$ and $\mathrm{Al}-\mathrm{Al} \mathrm{O}_{3}$ composites are bracketed by the bounds of equations (3) to (5). The Al-Be composite offers much greater grains in $\mathrm{M}$ than the $\mathrm{Al}-\mathrm{Al}_{2} \mathrm{O}_{3}$ composite.

\section{Composite Design for Specific Thermal Properties}

Thermo-mechanical design involves the specific heat, $\mathrm{C}_{\mathrm{p}}$, the thermal expansion, $\alpha$, the conductivity $\lambda$, and the diffusivity, a. These composite properties are bounded by equations (8)(13). They are involved in a number of performance indices. One is the criterion for minimising thermal distortion $M=\lambda \alpha$

Figure 5 shows a small part of the $\lambda-\alpha$ materials selection chart, with a grid of lines of the index $\mathrm{m}$ superimposed on it. Three groups of materials are shown, aluminium alloys, boron nitride $(\mathrm{BN})$ and silicon carbide $(\mathrm{SiC})$. The thermal properties of $\mathrm{Al}-\mathrm{BN}$ and $\mathrm{Al}-\mathrm{SiC}$ are bracketed by lines which show the bounding equations. The plot reveals immediately that SiC reinforcement in aluminium increases performance (as measured by $M$ ); reinforcement with $\mathrm{BN}$ decreases it. 


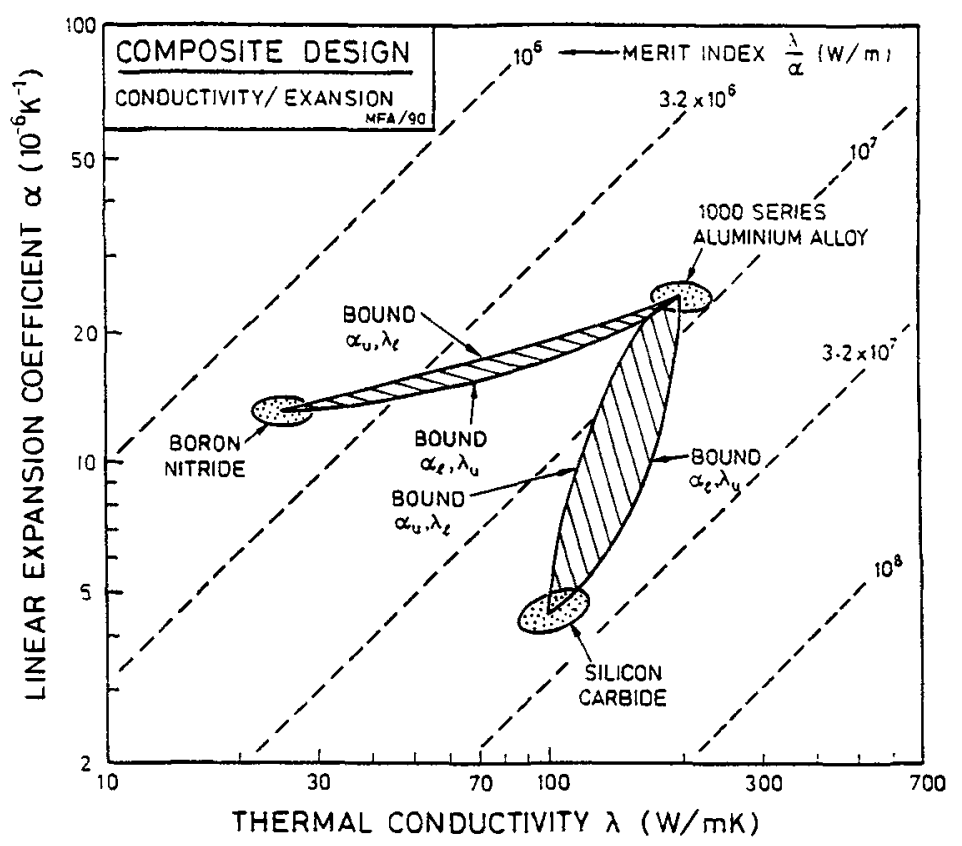

Fig. 5. A part of expansion coefficient-thermal conductivity space, showing aluminium alloys, boron nitride and silicon carbide. The properties of Al-BN and Al-SiC composites are bracketed by the bounds described by equations (9)-(12). The Al-SiC composites have better values of the index $M$ (which increases towards the bottom right) than the Al-BN composites.

\section{SUMMARY AND CONCLUSIONS}

Developing a new composite is a long and expensive business. It is helpful, before starting, to have an idea of what its strengths and weaknesses might be and where its applications might lie. The paper outlines a procedure for doing this. It combines the ideas of performance indices, materials selection charts and bounds or limits for composite properties to identify the composites which, potentially, have attractive combinations of mechanical and thermal properties. Further examples can be found in reference [1].

\section{REFERENCES}

[1] Ashby, M.F. Acta Metall. et Mater., 41, (1993), 1313 - 1335.

[2] Ashby, M.F.. "Materials selection in mechanical design", Pergamon Press, Oxford, (1992). 